\title{
Novel Modeling of Parameters Related to Intra-Firm Diffusion Innovation
}

\author{
Bosson-Amedenu Senyefia ${ }^{1}$, Acquah Joseph ${ }^{1}$, Eric Justice Eduboah ${ }^{2}$ and Noureddine Ouerfelli ${ }^{3}$ \\ ${ }^{1}$ Department of Mathematical Sciences, University of Mines and Technology, P.O. Box 237, Tarkwa, Ghana \\ ${ }^{2}$ Department of Economics Education, University of Education, P.O. Box 25, Winneba, Ghana \\ ${ }^{3}$ Université de Tunis El Manar, Laboratoire de Biophysique et Technologies Médicales LR13ES07, Institut \\ Supérieur des Technologies Médicales de Tunis, 9 Avenue Dr. Zouhaier Essafi 1006 Tunis, Tunisie \\ Correspondence: Bosson-Amedenu, Senyefia, Department of Mathematical Sciences, University of Mines and \\ Technology, P.O. Box 237, Tarkwa, Ghana.
}

Received: July 10, 2021 Accepted: September 29, 2021 Online Published: October 20, 2021

doi:10.5539/jmr.v13n6p1 URL: https://doi.org/10.5539/jmr.v13n6p1

\begin{abstract}
In this paper, we present a novel intra-firm diffusion model to predict the variation of Penetration Level (PL) with the Intensity of Use (IU) and Speed of Adoption (SA) with respect to information and communication technologies (I.C.T) within Tunisian Small Medium Enterprises (SMEs). The study was motivated by the work of Youssef et al., (2014), and its inspired data scope/range. The method of modeling focuses on optimization and non-linear regression. The first model has the capacity to compute the variation of PL with IU. However, this first model was modified to a second model through transformation in order to derive physical meaning to the parameters. The modified second model shows a quasi-vertical curvature which approximates the reciprocal of hyperbolic tangent. The Variation of PL with the SA was computed using the second model which estimated the parameters with the variables explaining about $62 \%$ variation in PL with SA $\left(\chi^{2}=0.0655, R^{2}=0.61651\right)$. We further formulated a third model to predict correlation of SA with PL, while imposing boundary assumptions to avoid problems of divergence; with the final model having a PL as the only adjustable parameter. The model exhibited a plateau effect at points $(0.9933,0.4373)$ and $(0,0)$ between two steeply vertical asymptotes at -0.06105 and 1.0013 , respectively. The developed model can be useful for eliciting information when data from different countries (or surveys) are compared for same or different span time through examining the behavior of the parameters, especially after Covid-19 era.
\end{abstract}

Keywords: intra-firm diffusion, penetration level, I.C.T, intensity of use, speed of adoption, SME's

\section{Introduction}

Oladipo et al. (2020) after reviewing literature identified that the parameters that control I.C.T usage are highly causative. Penetration of I.C.T has been found to be the backbone of development in High-, Middle- and Low-income countries depending on the extent of investment in I.C.T. Frontier economy coupled with speedy economic growth and development are hinged on the penetration of modern means of I.C.T. In modeling performance of I.C.T., the parameters which include penetration level, Intensity of use and the SA are sufficient indicators (Batuo, 2015). Furthermore, I.C.T penetration has more than doubled in some regions of the world since 2000 (ITU, 2018). Hwang and Shin (2017) found that I.C.T. investments play a salient role in economic growth in Korea. Latif et al. (2018) also found a causal relationship between economic growths, I.C.T. and other macroeconomic variables. Again, I.C.T in recent years have attracted extensive amount of investment from both the public and the private sectors especially due to COVID-19.

In an explorative survey aimed at identifying the training needs of entrepreneurs and employees within SMEs from the Suceava, Chernivtsi, and Bălți regions of Romania, Carmen et al. (2020) found among others that I.C.T investment improved work processes within SME's.

Lockdowns or social distancing policies which have been enforced in many countries with the aim of controlling the spread of COVID-19 have led to the unavoidable surge in the use of digital technology worldwide. This surge exposes the struggle to ensure continuity of delivery of services which hitherto required face-to-face interaction. With more countries experiencing the second and third wave of the pandemic, it is expected that digital technology penetration, intensity and speed of usage would be further deepened due to restrictions imposed on face-to-face practice mostly for non-essential service category. The intensity, penetration and speed of use of digital technology are expected to vary during the periods of relaxation or enforcement of lockdown measures; especially as the uncertainties associated with COVID-19 intensify 
(Faye et al., 2020).

In the pre-Covid-19 era, captured in the work of Youssef et al. (2014), Digital Technology was classified under three heterogeneous clusters which included the; (1) first wave technologies such as fixed phones, desk top computers and software's that serve a general purpose; (2) Second wave technologies which include internet, e-mail, free software, specific software and mobile phones; and (3) Third wave technologies such as intranet, laptops, video conference and electronic data interchange (EDI). The resulting model was S-shaped (sigmoid), where the first wave technologies with high speed of adoption and intensity of use were found to be localized on top of the curve. With the emergence of COVID-19 which had the necessitated the frequent use of digital technologies, it would be of interest to scientifically determine any change in the classified digital technologies with respect to the three parameters such as intensity of use, penetration and speed of use in this pro-COVID era.

In light of the spontaneous nature in which most nations are shifting to digital technological services (due to the uncertainties associated with the long period of COVID-19) in their quest to adjust to the new COVID-19 era, there is burgeoning need for to study the correlation between the three parameters of penetration level (PL), Intensity of use (IU) and the speed of Adoption (SA) which control I.C.T patronage.

In this work, we set the basis for a future work on COVID-19 with respect to modeling intra-firm diffusion to predict the variation of PL with IU, PL with SA and SA with PL. Thus, the study seeks to model the variation of PL with IU and SA in I.C.T. usage within Tunisian SMEs; based on a data inspired from the work of Youssef et al. (2014) in a pre-COVID-19 era.

\section{Suggested Models}

Fig. 1 represents the variation of penetration Level (PL) with the Intensity of Use (IU). Due to the few experimental data points, we were forced to use certain boundary conditions to consolidate the nonlinear regression to converge and give physically valid results. For this fact, we have assumed that we can only have a penetration level $(\mathrm{PL}=0)$ if the intensity of use is also zero $(\mathrm{UI}=0)$. So, the mathematical suggested model must obey to the following conditions:

$$
\left\{\begin{array}{l}
\lim _{I U \rightarrow 0} P L=0 \\
\lim _{I U \rightarrow \infty} P L=1
\end{array}\right.
$$

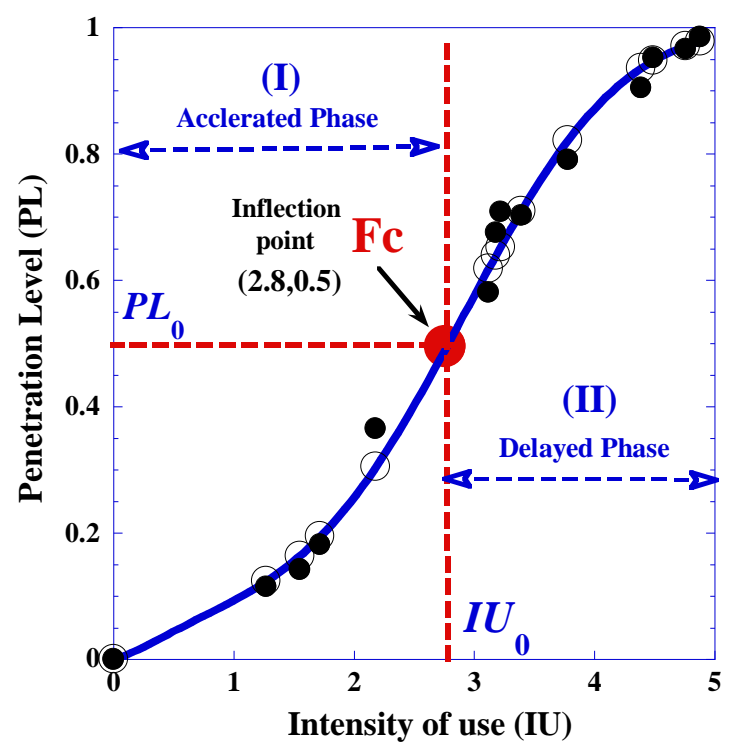

Figure 1. Variation of Penetration Level (PL) with the Intensity of Use (IU). (•): Experimental; (०): calculated with the Suggested model (Eq. 1)

Considering the rapid reaching to the limit and the change of curvature, we suggest the following exponential formcorrelating PL with IU:

$$
P L_{\text {calc }}=1-e^{-I U \cdot\left(a_{0}-a_{1} \cdot I U+a_{2} \cdot I U^{2}\right)}
$$

Where the $a_{\mathrm{i}}$ are three optimal adjustable parameters obtained by non linear regression and presented in the Table A. 
Table A. Optimal Parameters Values of Eq. 1

\begin{tabular}{|l|l|l|l|}
\hline Parameters of Eq. 1 & $a_{0}$ & $a_{1}$ & $a_{2}$ \\
\hline Value & 0.14055 & 0.085592 & 0.044738 \\
\hline
\end{tabular}

A mathematical function study permits us to determine the Inflection point $(\mathrm{F})$ which occurs at $\mathrm{IU}_{0}=2.8$ for which PL exceeds $50 \%\left(\mathrm{PL}_{0}=0.5\right)$. We can add that the inflection point $(\mathrm{F})$ delimits two phases of assimilation behavior such as accelerated and delayed phase (Fig. 1).

In this context, and for giving eventual physical significance of parameters, we make some transformations of the Eq. 1a' to be re-expressed as follows:

$$
P L_{\text {calc }}=1-e^{-\frac{I U}{I U_{c}} \cdot\left(1-\alpha_{1} \cdot I U+\alpha_{2} \cdot I U^{2}\right)}
$$

Where $\alpha_{i}$ are two dimensionless adjustable parameters and IUc is the characteristic Intensity of Use which represents the limiting value of IU for which PL reaches practically its limit (100\%). The obtained values by nonlinear regression are presented in the Table B. In addition, the IUc parameter sort of represents how quickly PL reaches the limit.

We note that physically that we can link the $\alpha_{i}$-coefficients to a particular intensity of use expressed as follows:

$$
\left\{\begin{array}{l}
I U_{1}=\frac{1}{\alpha_{1}} \\
I U_{2}=\frac{1}{\sqrt{\alpha_{2}}}
\end{array}\right.
$$

Table B. Optimal Parameters Values of Eqs... and ....

\begin{tabular}{|l|l|l|l|}
\hline Eq. 1c & IUc & $\alpha_{1}$ & $\alpha_{2}$ \\
\hline Value & 7.115 & 0.6090 & 0.04473830183 \\
\hline Eq. B & & $\mathrm{IU}_{1}$ & $\mathrm{IU}_{2}$ \\
\hline Value & & 1.6421 & 1.8202 \\
\hline
\end{tabular}

We remark that both the two values $\left(\mathrm{IU}_{1}\right.$ and $\left.\mathrm{IU}_{2}\right)$ are situated in the interval of accelerated phase $(\mathrm{I})$.

Fig. 2 represents the variation of penetration Level (PL) with the Speed of Adoption (SA). In the same context, due to the few experimental data points and some dispersion, we were forced to use certain boundary conditions to consolidate the nonlinear regression to converge and give physically valid results. For this fact, we have assumed that we can only have a penetration level $(\mathrm{SA}=0)$ if the intensity of use is also zero $(\mathrm{SA}=0)$. So, the mathematical suggested model must obey to the following conditions:

$$
\left\{\begin{array}{l}
\lim _{S A \rightarrow 0} P L=0 \\
\lim _{S A \rightarrow \infty} P L=1
\end{array}\right.
$$

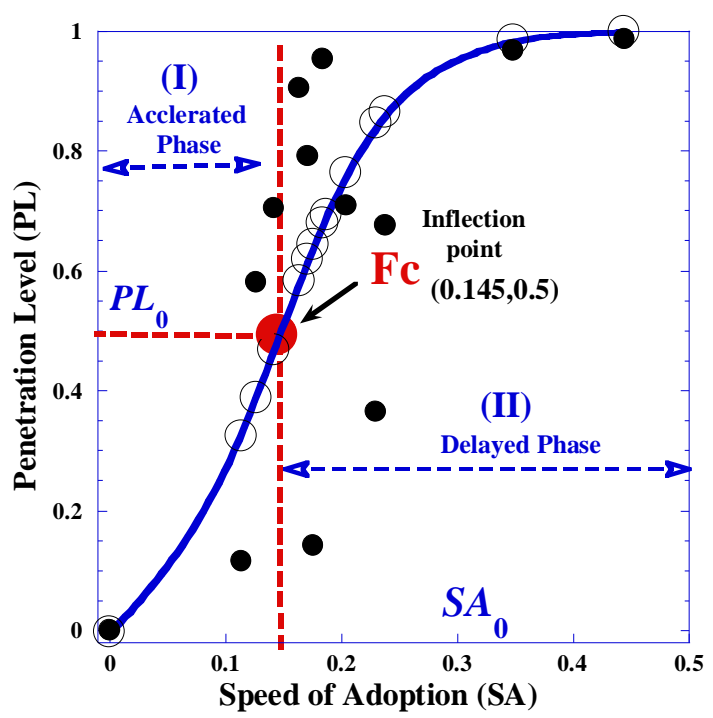

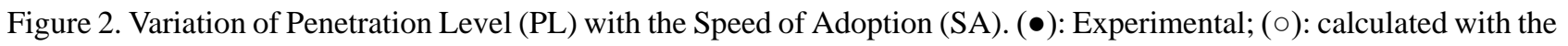
suggested model (Eq. 2) 
Around the PL-midst (Fig. 2), there is practically a vertical curvature, the shape of which approaches the inverse function of the hyperbolic tangent. For that, I suggest the following expression:

$$
y=y_{0}+t_{2} * \frac{e^{2 \frac{\left(x-x_{0}\right)}{t_{1}}}-1}{e^{2 \frac{\left(x-x_{0}\right)}{t_{1}}}+1}
$$

In this context, and for giving eventual physical significance of parameters, we make some transformations of the Eq. $2 \mathrm{a}$ " to be re-expressed as follows:

$$
P L=P L_{0}+P L_{1} * \frac{e^{2 \frac{\left(S A-S A_{0}\right)}{S A_{1}}}-1}{e^{2 \frac{\left(S A-S A_{0}\right)}{S A_{1}}}+1}
$$

Table 2. Estimated Parameters using a Nonlinear Regression Model

\begin{tabular}{|l|l|l|}
\hline Parameter & Value & Error \\
\hline $\mathrm{SA}_{0}$ or $x_{0}$ & 0.1424 & 0.06047 \\
\hline $\mathrm{PL}_{0}$ or $y_{0}$ & 0.46954 & 0.13167 \\
\hline $\mathrm{SA}_{1}$ or $t_{1}$ & 0.19144 & 0.13008 \\
\hline $\mathrm{PL}_{1}$ or $t_{2}$ & 0.53059 & 0.14646 \\
\hline & $R^{2}$ & $\mathrm{Chi}^{2} / \mathrm{DoF}$ \\
\hline & 0.61651 & 0.0655 \\
\hline
\end{tabular}

Nevertheless, regarding that the parameter $\left(t_{1}\right.$ or $\left.\mathrm{SA}_{1}\right)$ is responsible of the verticality trend (Fig. 2) which it needs to be more improved after the first nonlinear regression (Table 2). For this fact, we fix all parameters with the exception of $t_{1}$ to give more optimization and to obtain $t_{1}=0.09984$. We observe several points of convergence of the iteration of nonlinear regression. This stems from little number of data points and their great dispersion. We assume that there may be another better estimate.

Normally and due to symmetry, $y_{0}$ and $t_{2}$ must be equal to $0.5, x_{0}$ is the level of plateau of Figure 2 (SA) for which there is a change of phenomenon behavior and it's more shown in Figure 3.

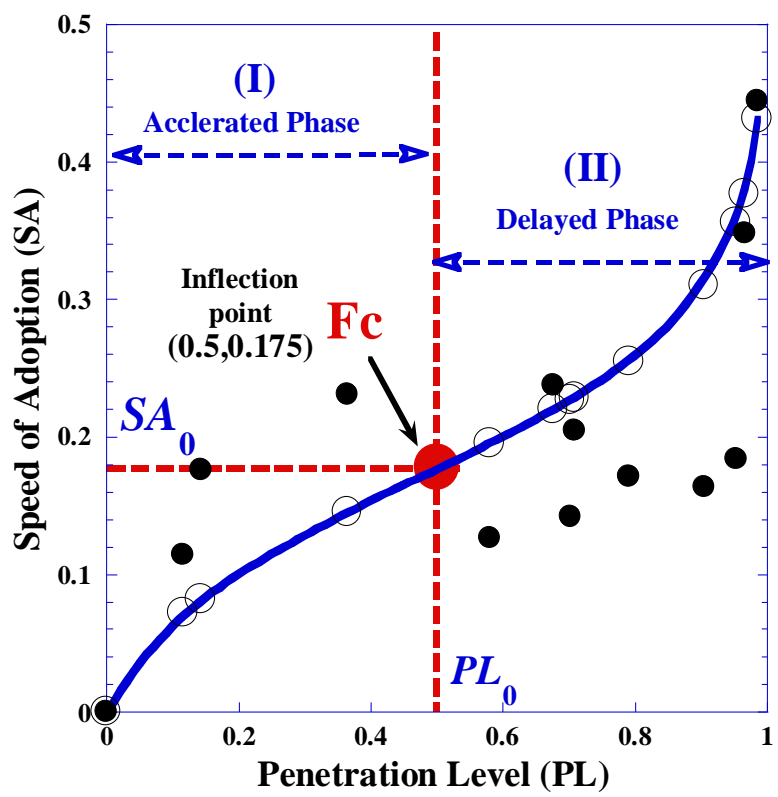

Figure 3. Variation of the Speed of Adoption (SA) with the Penetration Level (PL). (•): Experimental; (०): calculated with the Suggested Model (Eq. 3)

The reciprocal function expressed by Eq. 2 leads us to obtain the following expression:

$$
S A=S A_{0}+\frac{S A_{1}}{2} \ln \left(\frac{P L_{1}-P L_{0}+P L}{P L_{1}+P L_{0}-P L}\right)
$$


$\mathrm{PL}_{1}$ and $\mathrm{PL}_{0}$ values are very close to 0.5 because that theoretically, they are equal to 0.5 . Nevertheless, if we use 0.5 in regression, it can create some problems of divergence under the boundary limits or it can give some results out of the mathematical definition domain of the suggestion function.

$$
\left\{\begin{array}{c}
\mathrm{PL}_{1}>\mathrm{PL}_{0} \\
\mathrm{PL}_{1}+\mathrm{PL}_{0} \text { must be slightly }>1 \\
\mathrm{PL}_{1}+\mathrm{PL}_{0}=1+\varepsilon
\end{array}\right.
$$

Where $\varepsilon$ is a negligible positive value very near to zero. We obtain then the following numerical application on Eq. $3 \mathrm{a}$,

$$
S A=0.1424+\frac{0.09984}{2} \ln \left(\frac{0.53059-0.46954+P L}{0.53059+0.46954-P L}\right)
$$

Finally, we have:

$$
S A=0.1424+0.04992 * \ln \left(\frac{0.06105+P L}{1.00013-P L}\right)
$$

Nevertheless, we have fixed some variables and make one as a free adjustable parameter to obtain the minimum of discrepancy with experimental data. We obtain then the following optimal expression:

$$
S A=0.169785+0.06072 * \ln \left(\frac{0.06105+P L}{1.00013-P L}\right)
$$

The graph below exhibits a plateau effect between steeply vertical asymptotes. Vertical lines can be seen on the graph near the centre where the function grows without bound. These vertical lines are the vertical asymptotes. To find these asymptotes, we first find the derivative of the SA with respect to PL and equate the denominator function to zero (i.e., where the rational function is undefined).

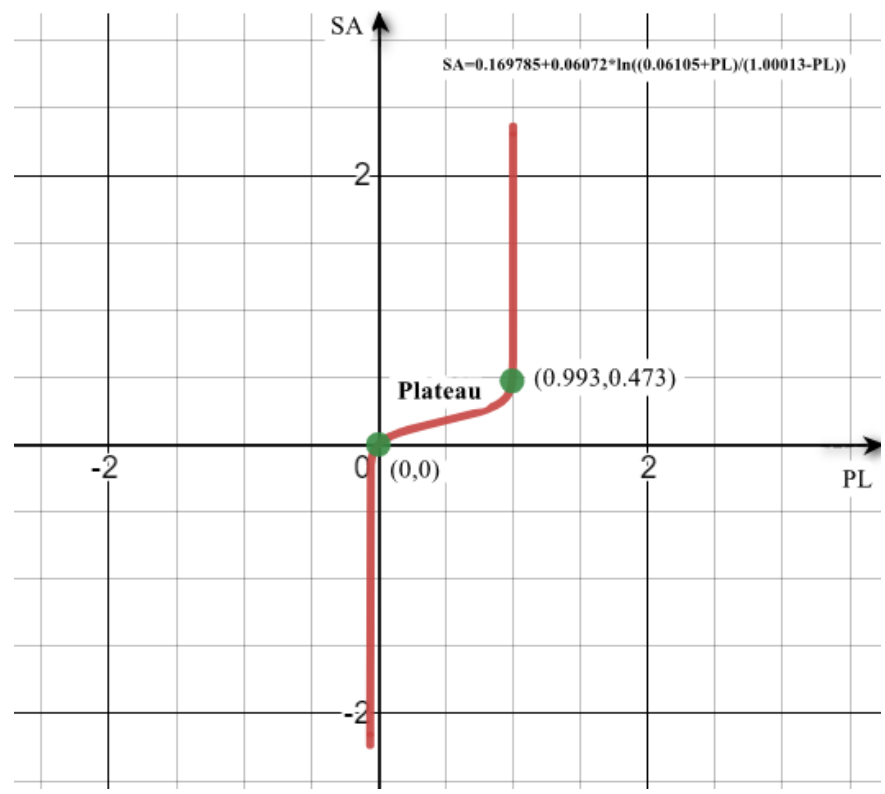

Figure 4. Graph Showing the Centre of Plateau

$$
\begin{aligned}
& \frac{d S A}{d P L}=0.06072\left[\frac{1}{\frac{0.06105+P L}{1.00013-P L}} \times \frac{d}{d x}\left(\frac{0.06105+x}{1.00013-x}\right)\right] \\
& \frac{d S A}{d P L}=0.06072\left[\frac{1.00013-P L}{0.06105+P L} \times \frac{d}{d x}\left(\frac{0.06105+x}{1.00013-x}\right)\right]
\end{aligned}
$$

Using the quotient rule and simplifying, we obtain

$$
\frac{d S A}{d P L}=0.06072\left[\frac{1.00013-P L}{0.06105+P L} \times \frac{1.06118}{(1.00013-P L)^{2}}\right]
$$




$$
\begin{gathered}
\frac{d S A}{d P L}=\left[\frac{0.06072}{(0.06105+P L)} \times \frac{1.06118}{(1.00013-P L)}\right] \\
\frac{d S A}{d P L}=\left[\frac{0.064435}{(0.06105+P L)(1.00013-P L)}\right]
\end{gathered}
$$

The function attains vertical asymptotes at $0.06105+P L=0$ so that $P L=-0.06105$ or at $1.00013-P L=0$ where PL= 1.0013

Table 3. Table showing Estimated Values of the Parameters using Formulated Model

\begin{tabular}{|l|l|l|l|l|l|}
\hline $\begin{array}{l}\text { Intensity } \\
\text { of Use }\end{array}$ & \multicolumn{3}{l}{ Penetration Level } & \multicolumn{2}{l|}{ Speed of Adoption } \\
\hline IUexp & PLexp & PLcal $_{1}$ & PLcal $_{2}$ & SAexp & SAcal $_{3}$ \\
\hline 0 & 0 & 0.0000 & -0.00316 & 0 & 0.0000 \\
\hline 1.27 & 0.115 & 0.12374 & 0.32332 & 0.11416 & 0.07172 \\
\hline 1.55 & 0.142 & 0.16374 & 0.64340 & 0.17637 & 0.08227 \\
\hline 1.72 & 0.182 & 0.19441 & 0.69312 & 0.18727 & 0.08181 \\
\hline 2.18 & 0.365 & 0.30450 & 0.84477 & 0.23041 & 0.14554 \\
\hline 3.18 & 0.676 & 0.63943 & 0.86409 & 0.23810 & 0.21967 \\
\hline 3.22 & 0.709 & 0.65311 & 0.76270 & 0.20450 & 0.22885 \\
\hline 3.78 & 0.791 & 0.82176 & 0.61865 & 0.17123 & 0.25508 \\
\hline 3.12 & 0.581 & 0.61867 & 0.38784 & 0.12690 & 0.19568 \\
\hline 3.39 & 0.703 & 0.70938 & 0.46659 & 0.14184 & 0.22713 \\
\hline 4.39 & 0.905 & 0.93623 & 0.58224 & 0.16393 & 0.31053 \\
\hline 4.49 & 0.953 & 0.94793 & 0.67938 & 0.18416 & 0.35612 \\
\hline 4.76 & 0.966 & 0.97141 & 0.98329 & 0.34843 & 0.37649 \\
\hline 4.88 & 0.986 & 0.97865 & 0.99764 & 0.44444 & 0.43121 \\
\hline
\end{tabular}

$\mathrm{PLcal}_{1}$ is the estimated value of PL using model 1 (Eq. 1).

$\mathrm{PLcal}_{2}$ is the estimated value of PL using model 2 (Eq. 2).

$\mathrm{SAcal}_{3}$ is the estimated value of SA using model 3 (Eq. 3).

Table 4. Standard Errors and Deviations of Formulated Models

\begin{tabular}{|l|l|l|}
\hline & SD & SE \\
\hline PLcal $_{1}$ & 0.03077 & 0.00822 \\
\hline PLcal $_{2}$ & 0.28884 & 0.077195 \\
\hline SAcal $_{3}$ & 0.08615 & 0.02303 \\
\hline
\end{tabular}

\section{Conclusion}

This paper was aimed at modeling the correlation between the parameters PL with IU, PL with SA and SA with PL that predict the I.C.T. usage of SMEs in Tunisia. The inflection point of the model occurs at IU $=2.8$ (for which PL exceeded $50 \%(\mathrm{PL}=0.5)$ ) with a limiting value of IUc $\approx 7.115$, being the threshold for which PL reaches its limit (100\%). The computed values for Intensity of use give an indication that the rate or motivation criterion for PL with SA is greatly accelerated. The model was used to estimate the correlations that exist between each pair of the three parameters. The first model predicted the variation of PL with IU. The modified second model predicted the variation of PL with the SA explaining about $62 \%$ variation in PL with $\mathrm{SA}\left(\chi^{2}=0.0655, R^{2}=0.61651\right)$. The third model which had an adjustable parameter, exhibited a plateau effect at the points $(0.9933,0.4373)$ and $(0,0)$ near the centre, between two steeply vertical asymptotes at PL $=-0.06105$ and 1.0013 predicted the correlation of SA with PL, while imposing boundary assumptions to avoid problems of divergence; with the final model having a PL as the only adjustable parameter. Due to the small data points and the dispersion of the scatter plot, we can deduce that the model is reliable. In conclusion, there is a causal correlation among the three parameters studied in this paper. The success of this model spurs on the formulation of similar models in this Covid-19 era which has been characterized with evolving penetration of I.C.T.

\section{Recommendation}

Future researchers may test the model on new surveys at recent periods and for other countries to see to how evolve the amplitude of parameters and conclude how this fact as a criterion or diagnostic for each specific situation. In this long period of Covid-19, the I.C.T is more developed in all countries, the electronic learning; administrations, correspondences, 
etc. augment considerably. So, it is excellent idea for any ulterior survey to clearly see changes of values of the parameters of the suggested equations which may lead to more physical meanings. The parameters of equations can give an idea of the intelligence (or speed of evolution of technologies etc), when we test it at different countries and or the evolution of intelligence when tested for different years.

\section{Acknowledgements}

We thank Drs. A.B. Youssef, W. Hadhri and H. M'Henni for fruitful discussions and, Drs. Rami B.H. Kacem (FSEGN, University of Carthage, Tunisia) and Olatunji a Shobande (University of Aberdeen, Aberdeen, UK) for useful correspondences.

\section{Conflict of interest}

The authors declare that they have no conflict of interest.

\section{References}

Youssef, A. B., Hadhri, W., \& M'Henni, H. (2011). Intra-firm diffusion of innovation: evidence from Tunisian SMEs in matters of informationand communication technologies. Middle East Development Journal, 3(1), 75-97. https://doi.org/10.1142/S1793812011000338

Oladipo, O. D., \& Wynand, G. (2020). Information and communication technology penetration level as an impetus for economic growth and development in Africa. Economic Research EkonomskaIstraživanja, 33(1), 1394-1418. https://doi.org/10.1080/1331677X.2020.1745661

Batuo, M. E. (2015). The role of telecommunications infrastructure in the regional economic growth of Africa. The Journal of Developing Areas, 49(1), 313-330. https://doi.org/10.1353/jda.2015.0005

Hwang, W., \& Shin, J. (2017). I.C.T-specific technological change and economic growth in Korea. Telecommunications Policy, 41(4), 282-294. https://doi.org/10.1016/j.telpol.2016.12.006

Faye M., Milne E., Marion B., \& Pereira F. L., (2020). Responding to COVID-19: New Trends in Social Workers' Use of Information and Communication Technology. Clinical Social Work Journal

Latif, Z., Latif, S., \& Ximei, L. (2018). Telematics and informatics the dynamics of I.C.T, foreign direct investment, globalization and economicgrowth: Panel estimation robust to heterogeneity and cross-sectionaldependence. Telematics and Informatics, 35(2), 318-328. https://doi.org/10.1016/j.tele.2017.12.006

Chașovschi, C. E., Nastase, C., Popescu, M., Scutariu, A. L., \& Condratov, I. A. (2021). Human Resources Training Needs in the Small and Medium Enterprises from Cros Border Area Romania-Ukraine Republic of Moldova. Sustainability 13, 21-50. https://doi.org/10.3390/su13042150

\section{APPENDIX A}

Table 5. Penetration Level, Intensity of Use and Time Required for a First Use of an I.C.T.

\begin{tabular}{|l|l|l|l|l|l|}
\hline & $\begin{array}{l}\text { Penetration } \\
\text { Level }\end{array}$ & $\begin{array}{l}\text { Penetration } \\
\text { Level }\end{array}$ & $\begin{array}{l}\text { Intensity of } \\
\text { Use }\end{array}$ & $\begin{array}{l}\text { Time } \\
\text { Required to } \\
\text { Use an I.C.T }\end{array}$ & $\begin{array}{l}\text { Speed of } \\
\text { Adoption }\end{array}$ \\
\hline & PL\% & PL & IU & T & SA = 1/ T \\
\hline Video conference & 11.5 & 0.115 & 1.27 & 8.76 & 0.11416 \\
\hline EDI & 14.2 & 0.142 & 1.55 & 5.67 & 0.17637 \\
\hline Intranet & 18.2 & 0.182 & 1.72 & 5.34 & 0.18727 \\
\hline Laptops & 36.5 & 0.365 & 2.18 & 4.34 & 0.23041 \\
\hline Email & 67.6 & 0.676 & 3.18 & 4.20 & 0.23810 \\
\hline Internet & 70.9 & 0.709 & 3.22 & 4.89 & 0.20450 \\
\hline Mobile Phone & 79.1 & 0.791 & 3.78 & 5.84 & 0.17123 \\
\hline Specific Software & 58.1 & 0.581 & 3.12 & 7.88 & 0.12690 \\
\hline Free Software & 70.3 & 0.703 & 3.39 & 7.05 & 0.14184 \\
\hline General Purpose Software & 90.5 & 0.905 & 4.39 & 6.10 & 0.16393 \\
\hline Office Computers & 95.3 & 0.953 & 4.49 & 5.43 & 0.18416 \\
\hline Fax & 96.6 & 0.966 & 4.76 & 2.87 & 0.34843 \\
\hline Fixed Phones & 98.6 & 0.986 & 4.88 & 2.25 & 0.44444 \\
\hline
\end{tabular}



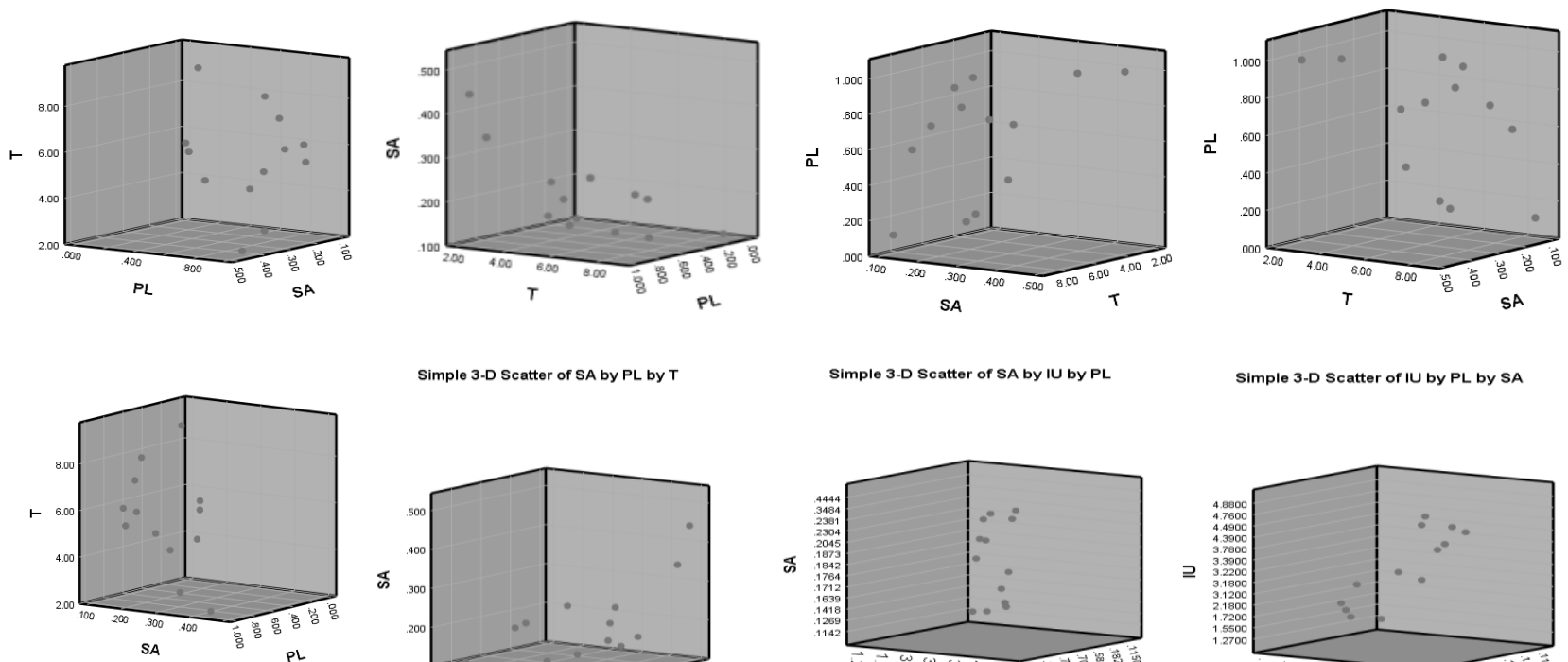

Simple 3-D Scatter of SA by PL by T

Simple 3-D Scatter of SA by IU by PL

Simple 3-D Scatter of IU by PL by SA
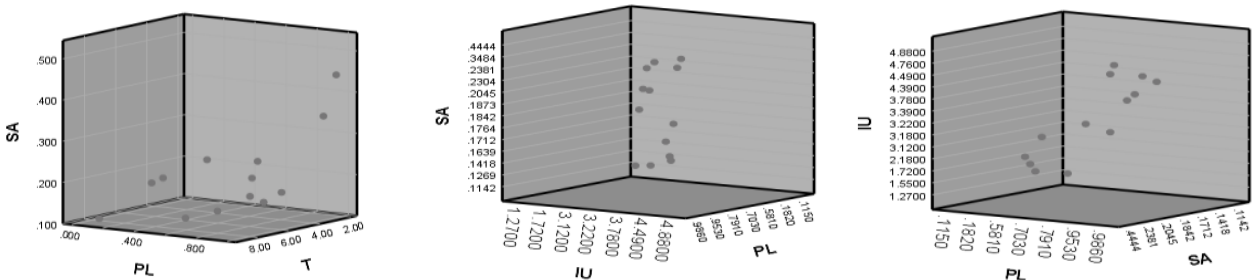

Simple 3-D Scatter of PL by SA by IU

Simple 3-D Scatter of IU by SA by PL

Simple 3-D Scatter of SA by PL by IU

Simple 3-D Scatter of PL by IU by SA
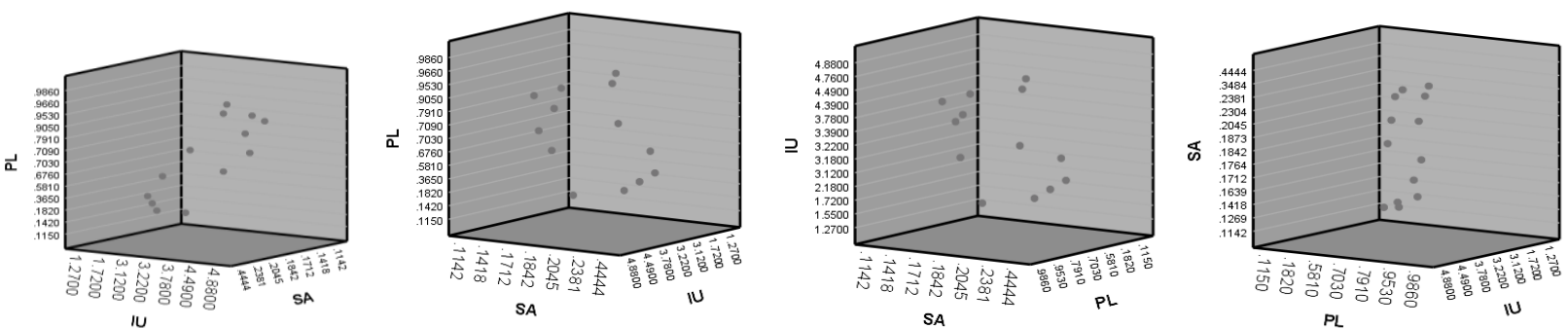

Figure 5. 3D Scatter Plot for Parameters

Table 6. 3D Parameters Interaction Effect

\begin{tabular}{|l|l|l|}
\hline$x$ & $y$ & $z$ \\
\hline PL/SA & IU/SA & SA \\
\hline PL*SA & IU*SA & SA \\
\hline PL*SA & PL*IU & PL \\
\hline PL*IU & IU*SA & IU \\
\hline
\end{tabular}


Table 7. Estimated Relationship between interactions of 3D Parameters

\begin{tabular}{|l|l|l|l|l|l|}
\hline PL/SA & IU/SA & PL*SA & IU*SA & PL*IU & PL/IU \\
\hline & & 0.0000 & 0.0000 & 0.0000 & \\
\hline 1.0074 & 11.125 & 0.013128 & 0.14498 & 0.14605 & 0.090551 \\
\hline 0.80514 & 8.7885 & 0.025044 & 0.27337 & 0.22010 & 0.091613 \\
\hline 0.97188 & 9.1848 & 0.034082 & 0.32210 & 0.31304 & 0.10581 \\
\hline 1.5841 & 9.4612 & 0.084101 & 0.50230 & 0.79570 & 0.16743 \\
\hline 2.8392 & 13.356 & 0.16095 & 0.75714 & 2.1497 & 0.21258 \\
\hline 3.4670 & 15.746 & 0.14499 & 0.65849 & 2.2830 & 0.22019 \\
\hline 4.6194 & 22.075 & 0.13545 & 0.64726 & 2.9900 & 0.20926 \\
\hline 4.5783 & 24.586 & 0.073731 & 0.39594 & 1.8127 & 0.18622 \\
\hline 4.9562 & 23.899 & 0.099716 & 0.48085 & 2.3832 & 0.20737 \\
\hline 5.5205 & 26.779 & 0.14836 & 0.71967 & 3.9729 & 0.20615 \\
\hline 5.1748 & 24.381 & 0.17551 & 0.82689 & 4.2790 & 0.21225 \\
\hline 2.7724 & 13.661 & 0.33659 & 1.6585 & 4.5982 & 0.20294 \\
\hline
\end{tabular}

\section{Copyrights}

Copyright for this article is retained by the author(s), with first publication rights granted to the journal.

This is an open-access article distributed under the terms and conditions of the Creative Commons Attribution license (http://creativecommons.org/licenses/by/4.0/). 